Journal of Engineering and Applied Sciences 14 (20): 7529-7534, 2019

ISSN: 1816-949X

(C) Medwell Journals, 2019

\title{
An Impact of Mergers and Acquisitions on Stock Price Behaviour of Acquiring Pharmaceutical Companies
}

\author{
${ }^{1} \mathrm{G}$. Abhishek and ${ }^{2} \mathrm{~N}$. Suresh \\ ${ }^{1}$ Ramaiah University of Applied Sciences, 560054 Bangalore, India \\ ${ }^{2}$ Faculty of Management and Commerce, Ramaiah University of Applied Sciences, \\ 560054 Bangalorem, India \\ nsuresh.ms.mc@msruas.ac.in
}

\begin{abstract}
In India, Pharma sector has been witnessed an acceptable growth in terms of mergers and acquisitions deals. In past few years, Indian Pharma companies have adopted the trend of mergers and acquisition deals between Foreign companies and domestic and firms. This study analyses the impact of mergers and acquisitions on profitability and stock price behaviour of acquiring companies by applying 27 days event window, the impact of such decision on the acquiring companie's share price. The data of share price at market price are collected for a period of 6 years $[-3,0,+3]$ event period. This study examines the effect on the share price by finding the abnormal return of the share price of acquiring companies using a 27 days $[-13,0,+13]$ day and 7 days $[-3,0,+3]$ event period. The expected return on the stock for each day was calculated using the CAPM Model. To analyze the stock price behavior "Autoregressive Conditional Heteroscedasticity" (ARCH) Model is used. Results reveals that, there has not been any remarkable effect of the abnormal return, performance of the market price developments are not only affected by the present figures but also, relates to several past information and future expectations of the share price. However, a fall in Cumulative Abnormal Return (CAR) has been noted which might be because of the fear of the failure of the acquisition in the minds of the shareholders.
\end{abstract}

Key words: Acquisitions, wealth effects, abnormal returns, cumulative returns, future expectations, shareholders

\section{INTRODUCTION}

Mergers and acquisitions is every time a planned progress with the Pharma companies in India and around the globe for development. One of the main reasons that lead to mergers and acquisitions is to increase the size of the company in terms of assets, geographical diversification, customer base, products, etc., in which it help the benefits of economies of scale. In spite of having Pharmacy Council of India with intense policy and pharma regulations (Kalaichelvan and Natarajan, 2015).

The Indian Pharma industry has been going through the processes of diversification, since, 1995. The economy of size and scale of operations is becoming increasingly important in the current situation, companies are using the mergers and acquisitions tool to strengthen their core competencies and work in a strategic position in as a global player. To be an effective player on the domestic and international market, companies must try to strengthen their core competencies and get rid of their extra burden in departments that are not profit in the process. Strategic alliances, mergers and acquisitions become a strategic tool for becoming a sufficiently competent player to survive in global competition (Manoj Kumara, 2015).

Literature review: The trends and progress of the mergers and acquisitions in Indian banking sectors and the study also examines impact of economic reforms in merger deals of Indian banks. The impact of merger events and analysis of the stock price behavior of acquirer as well as the target shareholders in the Indian banking industry (Shah and Deo, 2013). The performance evaluation of mergers and acquisitions of scheduled commercial banks in India comparing pre and post-merger financial performance of merged banks. Also, study discloses mergers and acquisitions in the Indian banking sector: a study of selected banks. Pre and post-merger comparison is conducted on selected variables to analyze the effectiveness of mergers and acquisitions on the banks. The change in the financial performance post-merger activity in Indian banking sector. An improvement in return to assets ratio and least impact on earnings per share and return to equity ratio in the merger

Corresponding Author: N. Suresh, Faculty of Management and Commerce, Ramaiah University of Applied Sciences, 560054 Bangalorem, India, nsuresh.ms.mc@msruas.ac.in 
cases taken as samples. The impact on the shareholder's wealth creation by calculating the abnormal return on the shares of SBI using a 27 days $[-13,0,+13]$ day and $7[-3$, $0,+3]$ event period (Chatterjee, 2016).

\section{MATERIALS AND METHODS}

Objective of the study: The study is generally $\operatorname{ARCH}(1,1)$ Model to check whether M\&A make impact on the share price of the acquiring companies (Jagannathan and Suresh, 2014) and perform cumulative abnormal test to analyze impact on the share price of the acquiring companies. Following steps are involved:

- To analyze the impact on the share price by calculating the cumulative abnormal return on the shares of acquiring companies using a 27 days [ $[-13$, $0,+13]$ day and $7[-3,0,+3]$ event period

- Developing ARCH family model with distribution in variance equation and mean equation with fixed degree of freedom with dummy variable to check the influence of the M\&A

\section{RESULTS AND DISCUSSION}

The focus of the current study is the stock price effects of companies M\&A's that occurred between 2014 and 2017 in India. To form our sample of M\&A transactions we set the following criteria:

- The date of the merger or acquisitions were selected between January 01, 2014 and December 31, 2017

- M\&As had been completed and not settled or withdrawn

- The acquiring companies were located in India

- Acquirers were listed companies in NSE and BSE

The above basis provide a final sample of 3 Pharma Companie's M\&A agreement of which all are listed companies. Lupin limited acquired with American Based GAVIS Pharma in 2016, acquisition increases the Lupine scale in the US generic market and also Lupin's pipeline in dermatology, controlled substance products and other high value and specific generic. GAVIS brings Lupin a highly skilled US based manufacturing and research organization that will complement Lupine Coral Springs, Florida's R\&D center for inhalation. GAVIS's New Jersey-based manufacturing facility also becomes the first manufacturing site of Lupine in America.

Reddy et al. (2013) laboratories acquired of mainstream brands of Belgian in 2015 with UCB in India. The firm also obtain the mainstream brands of the UCB in
India, Nepal, Sri Lanka and Maldives for Rs. 800 Crore. The company also confirmed to engross 350 employees active in undertaking the business in India. Reddy et al. (2013) has said undertaking UCB would raise its growth field of dermatology, respiratory and pediatrics.

Boards of India's two leading pharmaceutical companies, Sun Pharmaceuticals and Ranbaxy laboratories, announced their merger in April 2014. Being one of the largest M\&A deals in the Indian market, estimated at US $\$ 4$ billion, Sun Pharmaceuticals will acquire all outstanding shares of Ranbaxy in an all-stock transaction. Shareholders of Ranbaxy will get 0.8 shares of Sun Pharma for each Ranbaxy stock.

Cumulative abnormal return test: To analyze the effect of mergers and acquisition on the share price of the acquiring company an event window of 27 days consisting of the date of merger, 13 days pre and 13 days post-merger date has been selected. This would help us analyze the impact of the decision by acquiring companies on the share prices during the study period. We have also used a short event window consisting of 7 days $(-3,0,+3)$, i.e., 3 days of immediately preceding the merging date, the date of merger and 3 days post-merger.

The expected return on the stock for each day was calculated using the CAPM Model using the following equation:

$$
E(R t)=R f+\beta(R m-R f)
$$

Where:

$\mathrm{E}(\mathrm{R} t)=$ The Expected Return on the stock on day $\mathrm{t}$

$\mathrm{Rf}=$ Return on risk free security for day $\mathrm{t}$

$\mathrm{Rm}=$ Market Return for day $\mathrm{t}$

$\beta=$ Stock beta which measures the volatility of stock return with market return

Further, the abnormal return is calculated using equation:

$$
\mathrm{ARt}=\mathrm{Rt}-\mathrm{E}(\mathrm{Rt})
$$

Where:

$\mathrm{t}=$ Particular day relative to the event

Rt $=$ The actual Return of the stock for the day $\mathrm{t}$

Art $=$ Abnormal return of the security for day $t$

The cumulative abnormal return on the stocks has also been calculated during the event window.

Test result of 27 days event window $[-13,0,+13]$ : The cumulative abnormal return for $27[+13,0,-13]$ days event window have been graphically shown as: 


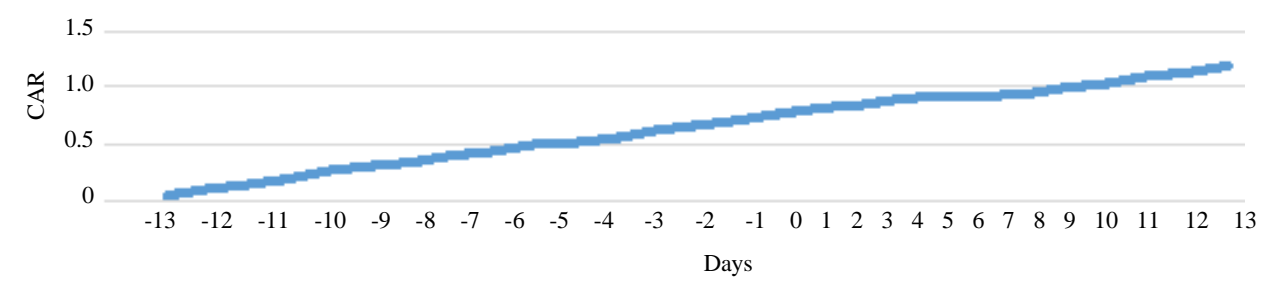

Fig. 1: The 27 days CAR of Lupin; CAR-27 days window

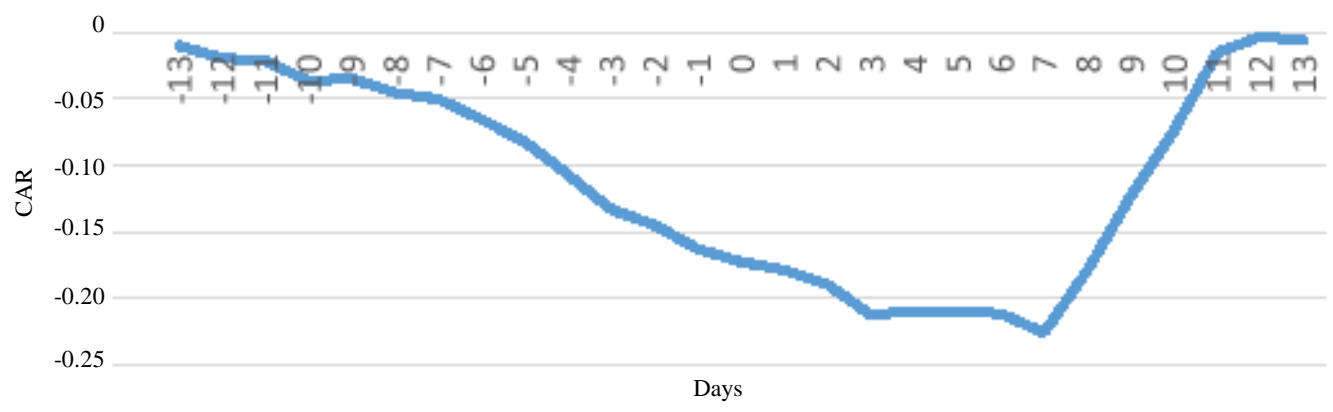

Fig. 2: The 27 days CAR of Dr. Reddy's Labs; CAR-27 days window

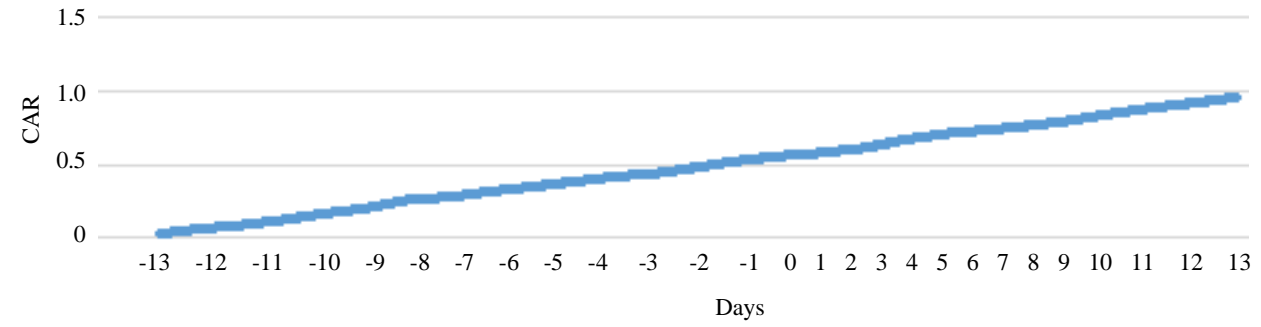

Fig. 3: The 27 days CAR of Sun Pharma; CAR-27 days window

Lupin's acquisition of US based Gavin: The 27 days cumulative abnormal return shows that though there has been an increase in the CAR immediately the date of merger. This shows that there has been positive impact of the acquisition on the shareholders return. It should also be noted that the CAR has been increasing post of the acquisition deal (Fig. 1).

Dr. Reddy's Laboratories acquisition of UCB: The 27 days cumulative abnormal return shows that though there has been an increase in the CAR immediately succeeding the date of merger, however, the CAR kept falling from the first day post date of acquisition. This shows that there has not been much positive impact on the date of acquisition on the shareholders return. It should also be noted that the CAR has been increasing again, since, the 7 th day post date of the acquisition deal (Fig. 2). This shows that, there was no sudden impact of the merger deal on the shareholders return.

Merger between Sun Pharma and Ranbaxy: The 27 days cumulative abnormal return shows that though there has been an increase in the CAR immediately the date of merger. This shows that there has been positive impact of the acquisition on the shareholder's return. It should also be noted that the CAR has been increasing post of the acquisition deal (Fig. 3).

Test result of 7 days event window $[-3,0,+3]$ Lupin's acquisition of US based Gavin: The 7 days cumulative abnormal return shows that though there has been an increase in the CAR immediately the date of merger (Fig. 4). This shows that there has been positive impact of the acquisition on the shareholders return. It should also be noted that the CAR has been increasing post of the acquisition deal.

Dr. Reddy's Laboratories acquisition of UCB: The 7 days cumulative abnormal return shows that though there fall in cumulative abnormal return post acquisition showing again that the shareholders do not have a very positive outlook towards the acquisition. This shows that there has been negative impact of the acquisition on the 


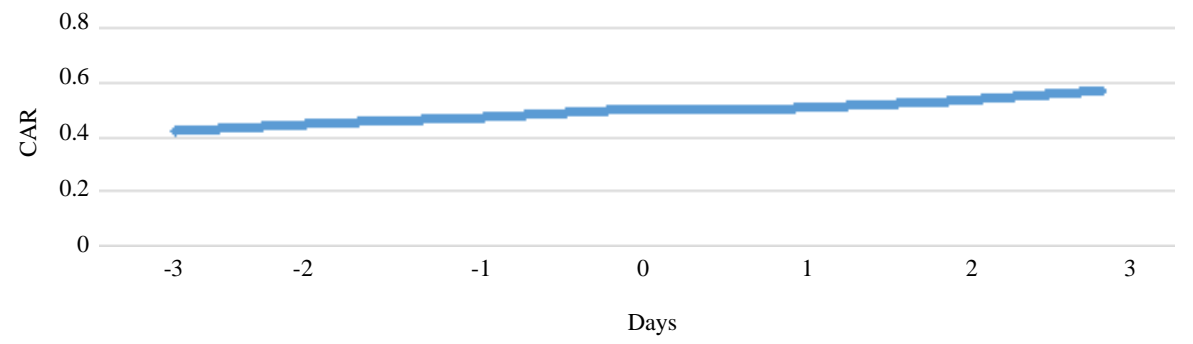

Fig. 4: The 3 days CAR of Lupin; CAR-3 days window

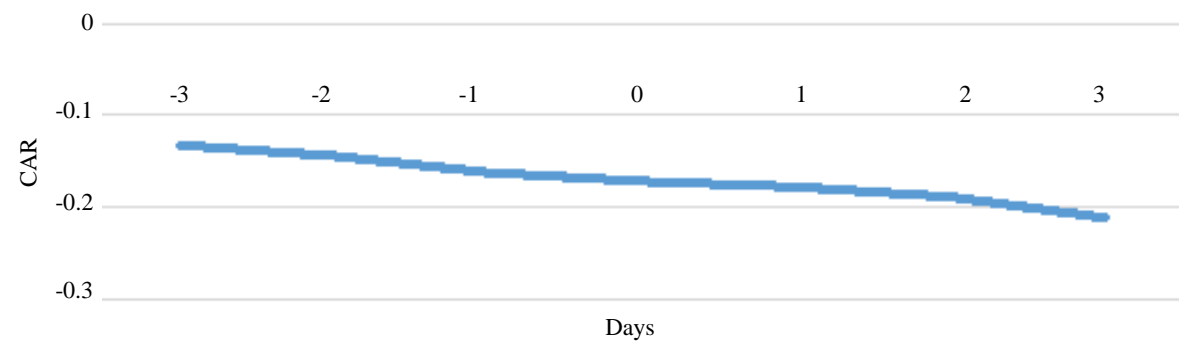

Fig. 5: The 3 days CAR of Dr Reddy's Labs; CAR-3 days window

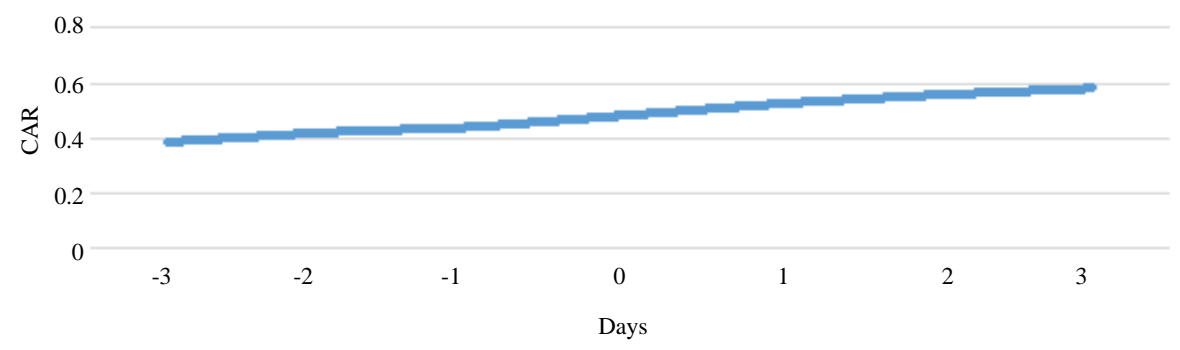

Fig. 6: The 3 days CAR of Sun Pharma; CAR-3 days window

shareholders return. It should also be noted that the CAR has been decreasing post of the acquisition deal (Fig. 5).

Merger between Sun Pharma and Ranbaxy: The 7 days cumulative abnormal return shows that though there has been an increase in the CAR immediately the date of merger. This shows that there has been positive impact of the acquisition on the shareholders return. It should also be noted that the CAR has been increasing post of the acquisition deal (Fig. 6).

Findings: Both the study of the $27[-13,0,+13]$ days event window and $7[-3,0,+3]$ days event window shows that there had been significant impact on the abnormal returns to the shareholders. While the share price and the cumulative abnormal return increased immediately the very next day of the merger. Thus, there seem to be a positive impact of the acquisition decision in the minds of the investors and hence, there is immediate wealth creation of the shareholders as reflected from the abnormal returns on stocks of acquiring companies.

GARCH Model: The ARCH model is suitable when the error variance in a time series follows an Autoregressive (AR) Model, the model is a Generalized Autoregressive Conditional Heteroskedasticity (GARCH) Model (Manasa and Narayanarao, 2018).

The estimation output header describes the estimation sample and the methods used for computing the coefficient standard errors, the initial variance terms and the variance equation.

The main output from ARCH estimation is divided into two sections the upper part provides the standard output for the mean equation while the lower part, labeled "variance equation", contains the coefficients, standard errors, z-statistics and p-values for the coefficients of the variance equation.

The ARCH parameters correspond to $\alpha$ and the GARCH parameters to $\beta$. The bottom panel of the output 
presents the standard set of regression statistics using the residuals from the mean equation. Note that measures such as $\mathrm{R}^{2}$ may not be meaningful, if there are no regresses in the mean equation.

Stock market shows volatility in the data, high volatility and low volatility is shown by the time series. GARCH/ARCH is commonly used in analyzing in finance because of arbitrary volatility. Before trying GARCH Model for the returns of the stock, heteroskedasticity test is done to check weather volatility exists or not. If it exists, then GARCH Model can be applied.

The development of the general $\operatorname{ARCH}(1,1)$ Model consists of two equations viz., mean equation and variance equation (Manohar et al., 2018):

$$
\text { Mean equation is: } R_{t}=\alpha_{0}+\alpha_{1} R_{t-1}+\varepsilon_{t}
$$

Where:

$\mathrm{R}_{\mathrm{t}}=$ Daily Return of dependent variable

$\mathrm{R}_{\mathrm{t}-1}=$ Daily return of independent variable

$\alpha_{0}=$ Constant

$\alpha_{1}=$ Coefficient of $\mathrm{R}_{\mathrm{t}-1}$

$\varepsilon_{\mathrm{t}} \quad=$ Residuals

$$
\text { Variance equation is: } h_{t}=\alpha_{0}+\alpha_{1} e_{t-1}^{2}+\beta_{1} h_{t-1}
$$

Where:

$\mathrm{h}_{\mathrm{t}}=$ Variance of residual term resultant from the mean Eq. 1

$\alpha_{0}=$ Constant

$\alpha_{1}=$ Coefficient of $\mathrm{e}_{\mathrm{t}-1}^{2}$

$\mathrm{e}_{\mathrm{t}-1}^{2}=\mathrm{ARCH}$ term

$\mathrm{h}_{\mathrm{t}-1}=\mathrm{GARCH}$ term

$\beta_{1}=$ Coefficient of $h_{t-1}$

To analyze the index and stock which have impact on the volatility, an exogenous Dummy variable $\mathrm{D}_{\mathrm{f}}$ is taken in the variance equation. If the dummy variable is found at 0.05 level of significance, the stock has an effect on the volatility of spot market. If this coefficient is found significant, it shows the stock transactions lead to change in the spot market volatility. Then the variance equation is as follows:

$$
h_{t}=\alpha_{0}+\alpha_{1} e_{t-1}^{2}+\beta_{1} h_{t-1}+\gamma_{1} D_{f}
$$

Where:

$\mathrm{D}_{\mathrm{f}}=$ Dummy variable

$\gamma_{1}=$ Coefficient of $\mathrm{D}_{\mathrm{f}}$

The model will be right when residuals satisfy for no serial correlation in the span of testing the serial correlation.

\section{Results and discussion of GARCH $(1,1)$ Model}

ARCH Model: Table 1 shows the volatility clustering of the daily return series of the NIFTY Pharma stocks and residuals, if NIFTY Pharma stocks which shows that there are long and short periods of low and high fluctuations and variations in the particular periods followed by respective high/low volatility. We also find residuals in the pattern, this is the justification of the ARCH family models. The best tool to measure the volatility is GARCH Model which is use to find the volatility of the spot market.

Table 1 shows the results of the GARCH Model of NIFTY Pharma stocks, $\alpha_{1}$ is ARCH term, $\gamma_{1}$ is GARCH term and $\beta_{1}$ is dummy variable which is stock futures return. ARCH term is significant for all the stocks. GARCH term is not significant as value is more than $1 \%$. To estimate the derivative transaction on the volatility of the spot market, dummy variable is introduced in the conditional variance Eq. 2 of the GARCH Model. The stock future return is significant in case of all the companies.

Here, Lupin's stock price is dependent variable and the NIHFTY Pharma is independent variable. Probability of NIFTY Pharma is $<0.05(5 \%)$, NIFTY Pharma is influencing the volatility of Lupin's stock price and null hypothes is can be rejected. The NIFTY Pharma is internal cause are significant of Lupin. Here DUMMY is an external variable which is $>0.05(5 \%)$ it is not significant, hence, it cannot effect the Lupin's volatility. But it influences the Lupin's stock price. Whereas, here, Dr. Reddy's stock price is dependent variable and the NIHFTY Pharma is independent variable. Probability of

Table 1: ARCH Model

Results of estimated ARCH Model ARCH $(1,1)$ Model:

Mean equation: $\mathrm{R}_{\mathrm{t}}=\mathrm{a}_{0}+\mathrm{a}_{1} \mathrm{R}_{\mathrm{t}-1}+\varepsilon_{\mathrm{t}} \quad$ (1)

Variance equation: $h_{t}=\alpha_{0}+\alpha_{1} e_{t-1}^{2}+\beta_{1} h_{t-1}+\gamma_{1} D_{f}$

(3)

\begin{tabular}{|c|c|c|c|c|c|c|}
\hline Companies & $\mathrm{a}_{0}$ & $\mathrm{a}_{1}$ & $\alpha_{0}$ & $\alpha_{1}$ & $\beta_{1}$ & $\gamma_{1}$ \\
\hline \multirow[t]{2}{*}{ Lupin } & -0.6843 & $6.6711^{* * *}$ & 1.9244 & $-2.9598^{* * *}$ & $2660.067^{* * * *}$ & 0.4700 \\
\hline & -0.4938 & 0 & 0.0543 & 0.0031 & 0 & 0.6384 \\
\hline \multirow[t]{2}{*}{ Dr. Reddys Labs } & $9.2809^{* * *}$ & $22.1832^{* * *}$ & 1.0661 & $2.5885^{* * *}$ & -0.3461 & -0.3786 \\
\hline & 0 & 0 & 0.2864 & 0.0096 & 0.7293 & 0.7050 \\
\hline \multirow[t]{2}{*}{ Sun Pharma } & -0.9850 & $17.8096^{* * *}$ & 0.8855 & $-2.3806^{* * *}$ & 1.0901 & -0.7961 \\
\hline & 0.3246 & 0 & 0.3759 & 0.0173 & 0.2757 & 0.426 \\
\hline
\end{tabular}
Mean equation

Variance equation

**Indicates statistical significance at 5\% level 
NIFTY Pharma is $<0.05(5 \%)$, NIFTY Pharma is influencing the volatility of Dr. Reddy's stock price and null hypothesis can be rejected. The NIFTY Pharma is internal cause are significant of Dr Reddy. Here, dummy is an external variable which is $>0.05(5 \%)$ it is not significant, hence, it cannot effect the Dr. Reddy's volatility. But it influences the Dr. Reddy's stock price.

Sun Pharma's stock price is dependent variable and the NIFTY Pharma is independent variable. Probability of NIFTY Pharma is $<0.05(5 \%)$, NIFTY Pharma is influencing the volatility of Sun Pharma's stock price and null hypothesis can be rejected. The NIFTY Pharma is internal cause are significant of Sun Pharma. Here, dummy is an external variable which is $<0.05(5 \%)$ it is not significant, hence, it cannot effect the Sun Pharma's volatility. But it influences the Sun Pharma's stock price.

\section{CONCLUSION}

The Indian Stock Market has been drastic functional and operative changes in the recent past. Mergers and acquisitions is every time a planned progress with the Pharma companies in India and around the globe for development. In this study, analyses the effect of mergers and acquisitions on profitability and stock price behaviour of acquiring companies by applying 27 days event window, the impact of such decision on the acquiring companie's share price. There has been significant impact in the shareholder's wealth post date of the acquisition. In the short term event study window of 7 days, the result showed that while the share price and the cumulative abnormal return increased immediately the very next day of the merger, it kept on increasing in subsequent days. The 27 days event window shows a broader aspect and there is a price increase in abnormal returns thereby increasing the return to shareholders from the 7 th day after the day of the acquisition of Dr Reddy acquisition with UCB. The acquisition has led to significant impact on the wealth creation or gaining abnormal returns for the shareholders of acquiring companies, this presenting that the market price fluctuation are influenced by the present data but also relates to several past information and future expectations of the shareholders. And ARCH effect is found in all the stock's and volatility in the GARCH Model. The stock future return is significant in case of all the companies.

\section{REFERENCES}

Chatterjee, D., 2016. Impact of the acquisition announcement by state bank of India of its associates on shareholders wealth: An event study. Acad. J. Goenka Coll. Commerce Bus. Administration, 1: 23-32.

Jagannathan, U.K. and N. Suresh, 2014. Risk/return of major Indian Stock Indices. MSRUAS. J. Manage. Commerce, 1: 1-4.

Kalaichelvan, K. and P. Natarajan, 2015. Efficacy of merger and acquisition in Indian banking industry a study with reference to select merged banks in India. Ph.D Thesis, Department of Commerce (SOM), Pondicherry University, Pondicherry, India.

Manasa, N. and S. Narayanarao, 2018. A study on impact of banknifty derivatives trading on spot market volatility in India. Acad. Accounting Financial Stud. J., 22: 1-9.

Manohar, G., S. Meghna and N. Suresh, 2018. Does all macro-economic factors contributes equally for Foreign Direct Investment (FDI) inflows in India?: An empirical study on macrovariables. Proceedings of the 8th International Conference on Advances in Economics, Management and Social Study-EMS, February 3-4, 2018, G Tower Hotel, Kuala Lumpur, Malaysia, ISBN:978-1-63248-146-7, pp: 10-16.

Manoj Kumara, N.V., 2015. Impact of Mergers and Acquisitions on Value of the Firm. University of Mysore, Mysore, India,.

Reddy, K.S., V.K. Nangia and R. Agrawal, 2013. Indian economic-policy reforms, bank mergers and lawful proposals: The ex-ante and ex-post lookup. J. Policy Model., 35: 601-622.

Shah, A. and M. Deo, 2013. Bank mergers and shareholder value creation in India. Intl. J. Bus. Soc., 14: $245-264$. 